\title{
Upregulation of Flk-1 by bFGF via the ERK pathway is essential for VEGF-mediated promotion of neural stem cell proliferation
}

\author{
Zhifeng Xiao ${ }^{1}$, Yaxian Kong ${ }^{1}$, Shufa Yang ${ }^{1}$, Meiyu Li $^{1}$, Jinhua Wen ${ }^{1}$, Lingsong Li $^{1}$ \\ ${ }^{1}$ Peking University Stem Cell Research Center and Cell Biology Department, Peking University Health Science Center, Beijing, \\ China
}

Neural stem cells (NSCs) constitute the cellular basis for embryonic brain development and neurogenesis. The process is regulated by NSC niche including neighbor cells such as vascular and glial cells. Since both vascular and glial cells secrete vascular endothelial growth factor (VEGF) and basic fibroblast growth factor (bFGF), we assessed the effect of VEGF and bFGF on NSC proliferation using nearly homogeneous NSCs that were differentiated from mouse embryonic stem cells. VEGF alone did not have any significant effect. When bFGF was added, however, VEGF stimulated NSC proliferation in a dose-dependent manner, and this stimulation was inhibited by ZM323881, a VEGF receptor (Flk-1)specific inhibitor. Interestingly, ZM323881 also inhibited cell proliferation in the absence of exogenous VEGF, suggesting that VEGF autocrine plays a role in the proliferation of NSCs. The stimulatory effect of VEGF on NSC proliferation depends on bFGF, which is likely due to the fact that expression of Flk-1 was upregulated by bFGF via phosphorylation of ERK1/2. Collectively, this study may provide insight into the mechanisms by which microenvironmental niche signals regulate NSCs.

Cell Research (2007) 17:73-79. doi:10.1038/sj.cr.7310126; published online 9 January 2007

Keywords: neural stem cells, vascular endothelial growth factor, fibroblast growth factor, embryonic stem cells

\section{Introduction}

Neural stem cells (NSCs) hold the capacity of self-renewal and can differentiate into neurons, astrocytes and oligodendrocytes. They play a major role in the development of the embryonic central nervous system and continue to function throughout adulthood [1-3]. The proliferation and differentiation of NSCs depend on microenvironmental niche signals $[4,5]$, including a number of growth factors such as vascular endothelial growth factor (VEGF) and basic fibroblast growth factor (bFGF) [6].

VEGF was originally identified as a major mediator of angiogenesis [7, 8]. It plays an important role in mediating vascular permeability and tissue regeneration $[9,10]$. In most occasions, VEGF exerts its action via its receptor,

\footnotetext{
Correspondence: Jinhua Wen

Tel: +86-10-82802224; Fax: +86-10-82802152;

E-mail: jhwen@bjmu.edu.cn

Received 7 October 2006; revised 7 December 2006; accepted 12 December 2006; published online 9 January 2007
}

Flk-1, in endothelial cells, hematopoietic stem/progenitor cells and some tumor cells [11-14]. In the central nervous system (CNS), for instance the hippocampus, VEGF stimulates the expansion of NSCs and neurogenesis in various animal models, resulting in improved learning ability [15-18]. In adults, NSCs are found in close proximity to blood vessels and surrounded by glial cells in the hippocampus and the subventricular zone. Previous studies by others suggested that both vascular cells and glial cells may serve as a niche for NSCs [19, 20]. Since both cell types express VEGF and bFGF [21], we hypothesize that these two growth factors may serve as niche signals for NSCs.

There are a number of observations suggesting that bFGF may also modulate neurogenesis, both in vivo and in vitro. First, bFGF and its main receptor, FGFR-1, are both present in the mouse CNS during corticogenesis [22]. Second, bFGF is secreted from cells within the brain through an energy-dependent exocytosis process [23]. Third, during the early phase of development, neural progenitor cells proliferate in response to bFGF during the 
neurogenic phase [24, 25]. It has been reported that knocking out bFGF during critical periods of brain development led to an overall reduction in progenitor proliferation and subsequent neuronal differentiation [26, 27].

To assess the roles of VEGF and bFGF in regulation of NSCs, we used a nearly homogeneous population of NSCs derived from mouse embryonic stem (ES) cells to test the hypothesis that bFGF and VEGF coordinately regulate NSC proliferation.

\section{Materials and Methods}

Neural induction of mouse ES cells

ES CGR8 cells were maintained in BHK21 medium containing $10 \%$ fetal bovine serum (GIBCO, NY, USA), $1 \mathrm{mM}$ sodium pyruvate (GIBCO), $0.1 \mathrm{mM} \beta$-mercaptoethanol (GIBCO), $1 \times$ non-essential amino acids (GIBCO), $1000 \mathrm{U} / \mathrm{ml}$ leukemia inhibitory factor (LIF, Chemicon, CA, USA) and $0.292 \mathrm{mg} / \mathrm{ml}$ glutamine (GIBCO), and passaged onto gelatin-coated dishes every other day [28]. ES cells were induced to differentiate into NSCs as reported by Okabe et al. [29]. Briefly, embryoid bodies were formed and kept in suspension by withdrawing LIF for 4 days, and then plated onto a tissue culture dish in Dulbecco's minimal essential medium (DMEM; GIBCO) with $10 \%$ fetal bovine serum for $24 \mathrm{~h}$. On the next day, the medium was changed to DMEM/F12 supplemented with $5 \mu \mathrm{g} / \mathrm{ml}$ insulin, $50 \mu \mathrm{g} / \mathrm{ml}$ transferring buffer, $30 \mathrm{nM}$ selenium chloride and $5 \mu \mathrm{g} / \mathrm{ml}$ fribronectin (ITSFn medium) (Sigma, MO, USA) for 7 days. NSCs selected from ITSFn were cultured on disk pre-coated with fibronectin $(50 \mu \mathrm{g} / \mathrm{ml}$; GIBCO) in DMEM/F12, supplemented with $1 \times \mathrm{N}_{2}(\mathrm{GIBCO})$ and 10 ng/ml bFGF (Pepro Tech EC, London, UK).

\section{Immunofluorescence and confocal microscopy}

NSCs were passaged on slides coated with fibronectin the day before detection. Cells were fixed in $4 \%$ paraformaldehyde at room temperature for $20 \mathrm{~min}$ followed by permeabilization with PBS containing $0.5 \%$ Triton $\mathrm{X}-100$ for $30 \mathrm{~min}$. After washing with PBS, the cells were blocked for $1 \mathrm{~h}$ at room temperature with PBS containing $5 \%$ secondary antibody serum, and then incubated with primary antibodies. To detect NSCs, the following primary antibodies were used: mouse anti-nestin (1:100, Chemicon, CA, USA), mouse anti-Bmi-1 (1:100, Upstate Biotechnology, NY, USA), rabbit anti-Sox-2 (1:150, Chemicon). After washing, slides were incubated with secondary antibodies (Jackson ImmunoResearch, PA, USA) conjugated with fluorescein isothiocyanate or tetramethylrhodamine isothiocyanate at room temperature for $30 \mathrm{~min}$. After washing, the slides were mounted with fluorescence mounting medium (VECTORS, CA, USA) containing 4V,6-diamidino-2-phenylindole (DAPI) and analyzed by immunofluorescent microscope (Leica, Wetzlar, Germany) or confocal laser scanning microscope (Leica).

\section{Reverse transcription polymerase chain reaction (RT-PCR)}

Total RNA was extracted with TRIZOL reagents (Invitrogen, MD, USA), following the manufacturer's instructions. Complementary DNA of extracted cells was subsequently synthesized from total RNA using a Ready-to-Go Kit (Amersham Pharmacia Biotech, NJ, USA). PCR was performed using Taq polymerase (Invitrogen). Forward and reverse primers were ( $5^{\prime}-3$ '): $\beta$-actin-for: ATG GAT GAC GAT ATC GCT G; $\beta$-actin-rev: TGA GGT AGT CTG TCA GGT ; nestin-for:
GGA GTG TCG CTT AGA GGT GC; nestin-rev: TCC AGA AAG CCA AGA GAA GC; Bmi-1-for: AGC AGA AAT GCA TCG AAC AA; Bmi-1-rev: CCT AAC CAG ATG AAG TTG CTG A; VEGFfor: ATG AAC TTT CTG CTC TCT TGG; VEGF-rev: TCA CCG CCT TGG CTT GTC ACA.

\section{VEGF enzyme-linked immunosorbent assay}

VEGF in culture supernatants were measured by using mouse VEGF ELISA Kit (R\&D System, MN, USA) following the manufacturer's instructions.

\section{RNA interference}

The small interference RNA (siRNA) (sense and antisense strands) was purchased from Genechem Company (Shanghai, China). The siRNA sequences used in this study were: for VEGF, sense: 5'-CAC ACA UUC CUU UGA AAU Adtdt-3', antisense: 5'-UAU UUC AAA GGA AUG UGU Gdtdt-3'; for nonsilencing control siRNA, sense: 5'-UUC UCC GAA CGU GUC ACG Udtdt-3'; antisense: 5'-ACG UGA CAC GUU CGG AGAA-3'. Transfection of cells was performed with the Lipofectamine 2000 reagent (Invitrogen) in 96-well plates (Nunc, Denmark) according to the manufacturer's instructions. Four hours after transfection, the cells were washed, and the media were changed to the normal growth medium. VEGF concentrations in the supernatant and cell proliferation were measured at 24,48 and $72 \mathrm{~h}$ after transfection.

\section{Proliferation assay}

Cell proliferation was evaluated by measuring tritiated thymidine incorporation. NSCs $\left(2-4 \times 10^{4} /\right.$ well $)$ were trypsinized and passaged onto flat-bottomed 96-well plates that were pre-coated with fibronectin at a volume of $200 \mu \mathrm{l}$ per well in the presence of $10 \mathrm{ng} / \mathrm{ml} \mathrm{bFGF}$. In the following days, the media is changed and cells are treated with various concentrations of recombinant VEGF $_{164}$ (Pepro Tech), ZM323881 (Calbiochem, Darmstadt, Germany). After 24 hours incubation, each well was added with $0.2 \mu \mathrm{Ci}$ of $\left[{ }^{3} \mathrm{H}\right]$ thymidine (specific activity: $1 \mathrm{Ci} / \mathrm{mmol}$, Amersham) for $12 \mathrm{~h}$. Cells were lysed by two freeze-and-thaw cycles, and harvested onto glassfibre filters (Perkin Elmer, MA, USA) with a 96-well plate harvester (Tomtec, USA). The cellular thymidine uptake was determined in liquid scintillation fluid (Perkin Elmer, Finland) with Liquid scintillation \& Luminescence counters (Perkin Elmer).

\section{Western blot analysis}

NSCs were starved in serum-free DMEM/F12 medium without bFGF for at least $12 \mathrm{~h}$. The cells were then incubated with or without $10 \mu \mathrm{M}$ of U0126, an inhibitor of MEK. Two hours later, VEGF $(100 \mathrm{ng} / \mathrm{ml})$, bFGF $(10 \mathrm{ng} / \mathrm{ml})$ or both were added. After incubation for $30 \mathrm{~min}$, the cells were collected and lysed in lysis buffer (50 mM Tris-Cl pH 8.0, $150 \mathrm{mM} \mathrm{NaCl}, 1 \%$ Nonidet P-40, $0.1 \%$ sodium dodecyl sulfate (SDS), $1 \%$ Triton X-100) containing protease inhibitors. Total protein concentration was determined by Bradford assay. Equal amounts $(30 \mu \mathrm{g})$ of total protein were separated by $10 \%$ SDS-polyacrylamide gels (SDS-PAGE). The protein was electrophorectically transferred to a PVDF membrane. After blocking in 5\% nonfat milk for $1 \mathrm{~h}$ at room temperature, the membranes were incubated overnight at $4^{\circ} \mathrm{C}$ with various primary antibodies raised against total and phosphorylated ERK1/2 (1:1000, Santa Cruze). After extensive wash with PBS containing $0.1 \%$ Tween-20, the membranes were then incubated with horseradish 
peroxidase-conjugated secondary antibody (1:1 000, Santa Cruz) for $1 \mathrm{~h}$ at room temperature. The membranes were then washed with PBS containing $0.1 \%$ Tween-20 and the signals were visualized using the enhance chemiluminescence system (ECL) (PerkinElmer). After being "stripped", the membranes were re-probed with antibody against Flk-1 (1:1 000, Santa Cruze) or with antibody against $\alpha$-tubulin as a loading control.

\section{Statistics}

All experiments were repeated at least three times. The statistical significance of differences was evaluated by Student's $t$-test for single comparison, and by ANOVA followed by post hoc $t$-tests for multiple comparisons. All statistical tests were two-sided. Significance was taken as $P<0.05$.

\section{Results}

A nearly homogeneous population of NSCs was derived from ES cells

When ES cells were induced to differentiate into NSCs, the cells became small and elongated. After three passages in the presence of $10 \mathrm{ng} / \mathrm{ml}$ of bFGF, a virtually uniform cell population was established. We confirmed the successful differentiation of ES cells into NSCs by immunofluoresence and confocal microscopy. More than 95\% of the NSCs expressed nestin and Bmi-1 (Figure 1A). None of these markers were expressed in ES cells. Bmi-1

A

NSCs
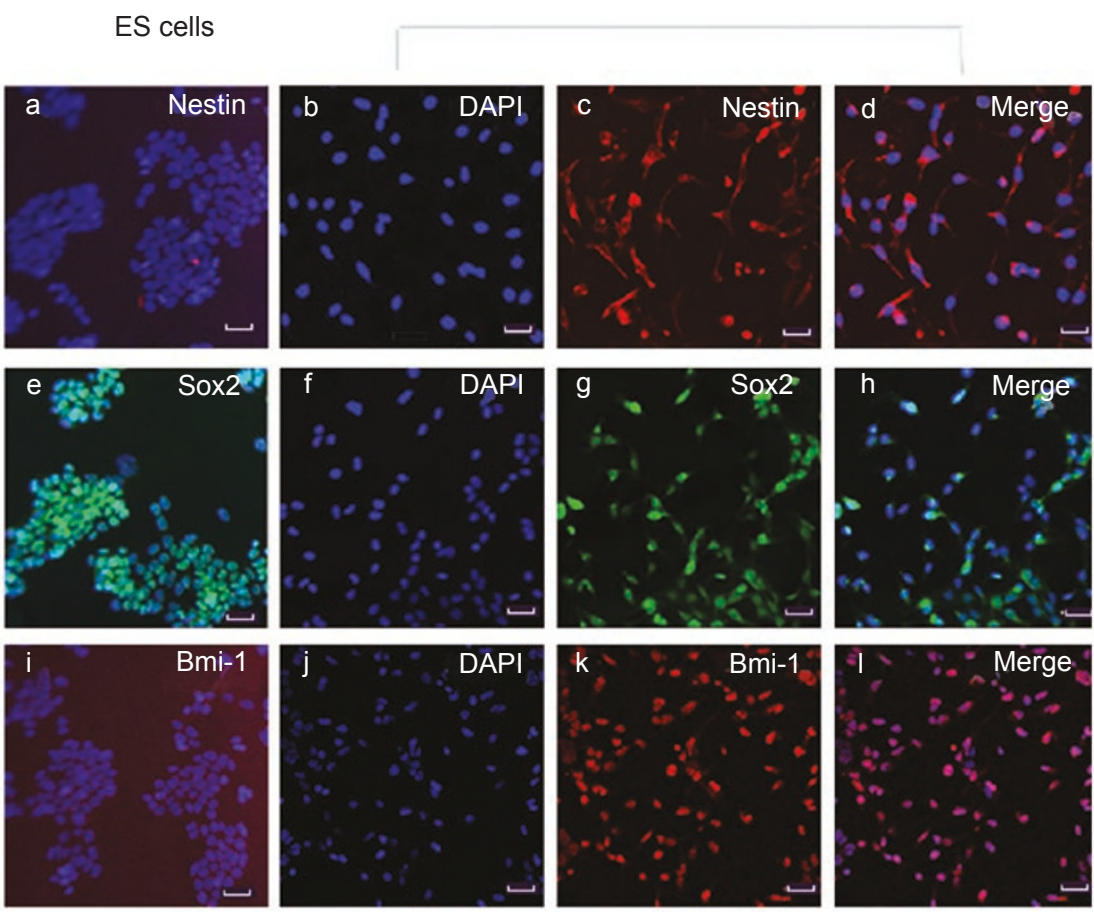

B

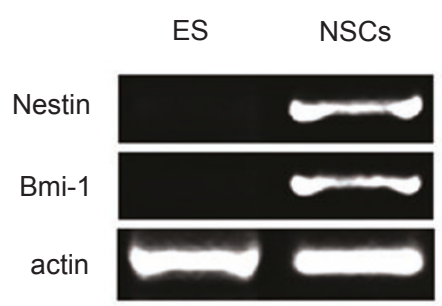

Figure 1 Characterization of NSCs derived from ES cells. (A) Immunofluorescence analysis of ES cells and NSCs derived from ES cells. (a) Absence of nestin expression in ES cells; (b-d) more than 95\% of the neural stem cells expressed nestin; (e-h) both ES cells (e) and NSCs (f-h) expressed Sox-2; (i) absence of Bmi-1 expression in ES cells; (j-1) more than 95\% of the NSCs expressed Bmi-1. (B) The expression of nestin and Bmi-1 in NSCs was confirmed by RT-PCR. Sox-2 was not tested because the gene consists only of a single exon. Scale bar $=40 \mu \mathrm{m}$. 
is required for the post-natal maintenance of stem cells in multiple tissues including the CNS and peripheral nervous system. On the other hand, the stem cell marker Sox-2 was expressed in both ES cells and NSCs. More than 95\% of the cells expressed NSC makers such as nestin, Bmi-1 and Sox-2, suggesting that this NSC population is nearly homogeneous. The expression of nestin and Bmi-1 was further confirmed by RT-PCR (Figure 1B).

\section{VEGF promoted the proliferation of NSCs via Flk-1}

NSCs were cultured in DMEM/F12 supplemented with $1 \times \mathrm{N}_{2}$ and $10 \mathrm{ng} / \mathrm{ml}$ of bFGF. To analyze the dose-dependent effect of VEGF, NSCs were treated with various amounts of exogenous VEGF. As demonstrated by tritiated thymidine incorporation, exogenous VEGF promoted the proliferation of NSCs in a dose-dependent manner. The maximal effect occurred at a VEGF concentration of 100 $\mathrm{ng} / \mathrm{ml}$ (Figure 2A).

To test whether VEGF mediates its action via Flk-1, we tested tritiated thymidine incorporation in the presence
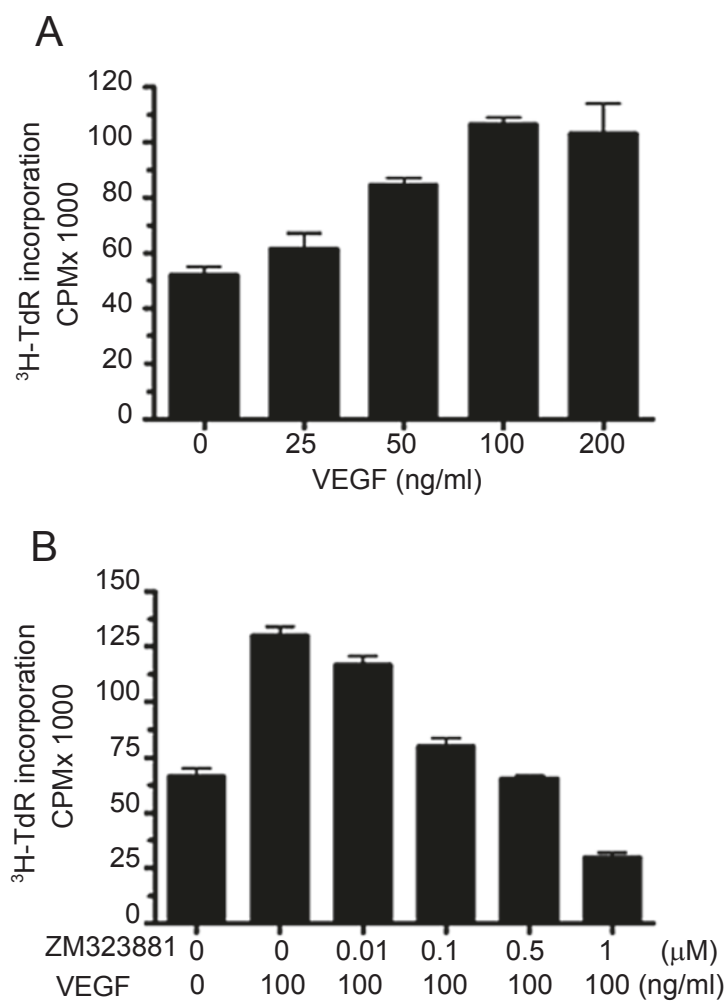

Figure 2 VEGF stimulated neural stem cell proliferation via Flk-1. (A) Exogenous VEGF stimulated NSC proliferation in a dose-dependent manner as measured by tritiated thymidine incorporation. (B) ZM323881, an Flk-1 inhibitor, suppressed VEGF-induced NSC proliferation in a dose-dependent manner. of exogenous VEGF and ZM323881, a specific inhibitor for Flk-1. Indeed, ZM323881 inhibited NSC proliferation (Figure 2B). Interestingly, the Flk-1-specific inhibitor ZM323881 also inhibited NSC proliferation in a dose-dependent manner even when no exogenous VEGF was added (Figure 3A). This result suggests that endogenous VEGF contributes to NSC proliferation through an autocrine mechanism. To support this speculation, RT-PCR was performed and the results showed that NSCs indeed expressed three VEGF isoforms: VEGF120, VEGF164 and VEGF188 (Figure 3B). An increasing amount of VEGF protein was also detected in a time-dependent manner in the supernatant of NSC cultures using ELISA (Figure 3B).

We further tested the effect of endogenous VEGF on NSC proliferation by siRNA-mediated knockdown. As shown in Figure 3, VEGF concentrations in the culture supernatant (Figure 3C) and in the cell lysate (Figure 3D) were both reduced to $50 \%$ of the control level $72 \mathrm{~h}$ after the siRNA transfection. Accordingly, inhibition of NSC proliferation was observed at $48 \mathrm{~h}$ and became more prominent $72 \mathrm{~h}$ after the siRNA transfection (Figure 3E). Inhibition of NSC proliferation by siRNA transfection could be partially reversed by addition of $100 \mathrm{ng} / \mathrm{ml}$ of exogenous VEGF (Figure 3F).

To determine whether blocking VEGF signaling could induce NSC apoptosis, which would affect the total number of viable NSCs in culture, the Annexin V-positive NSCs were detected by flow cytometry. The result revealed that cell apoptosis was not increased after the application of the VEGF receptor inhibitor ZM323881 (not shown), suggesting that inhibition of VEGF signaling does not lead to NSC apoptosis.

Phosphorylation of ERK is essential for bFGF-induced Flk-1 expression and the subsequent effect of VEGF on NSC proliferation

bFGF promoted the proliferation of NSCs in a dosedependent manner and became more prominent in the presence of $100 \mathrm{ng} / \mathrm{ml}$ of VEGF (Figure 4A). In contrast to bFGF, VEGF alone did not have any effect on the proliferation of NSCs without bFGF. In the presence of bFGF, however, VEGF promoted the proliferation of NSCs in a dose-dependent manner (Figure 4B).

To investigate the reason why the effect of VEGF depends on bFGF, we measured Flk-1 expression levels in NSCs cultured in media with or without bFGF. As shown in Figure 4D, Flk-1 expression was upregulated in NSCs by bFGF treatment, and this elevation was blocked by U0126, a specific inhibitor for ERK1/2 phosphorylation (4D). In agreement with this observation, active phosphorylated ERK $1 / 2$ in these cells was increased in the presence of bFGF. VEGF alone did not have any effect on ERK1/2 
A

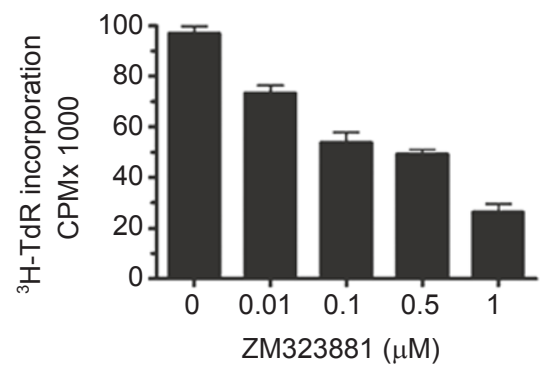

C

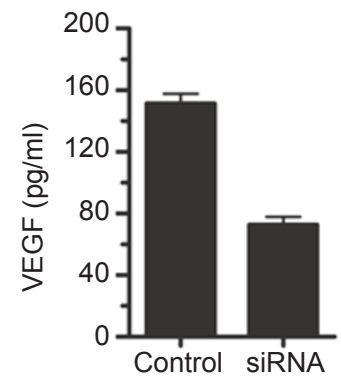

$E$

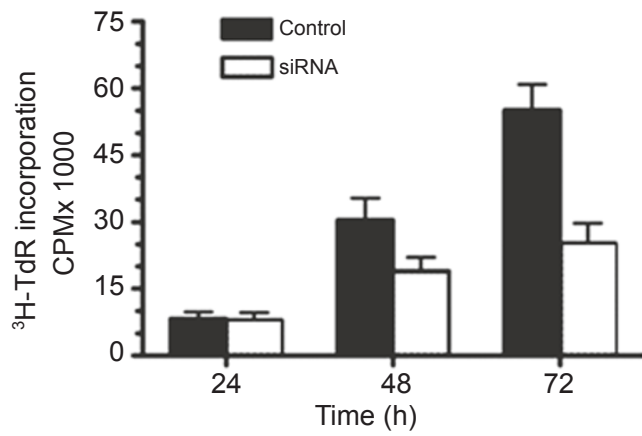

B
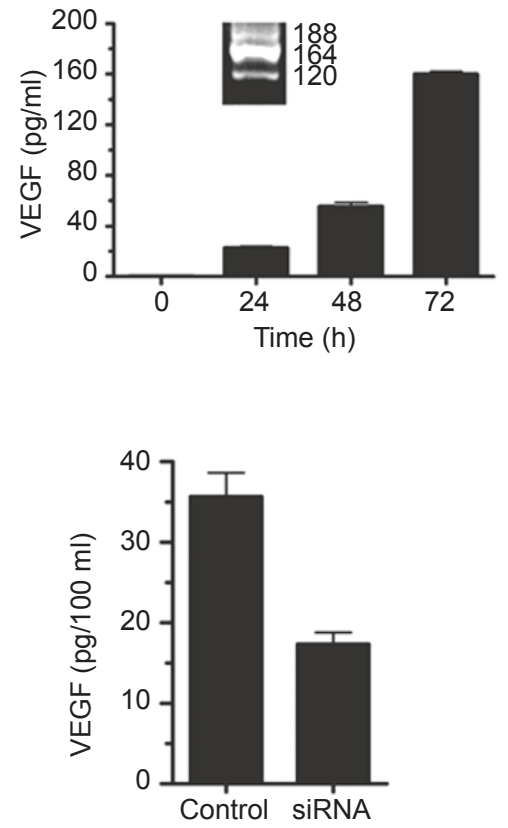

$\mathrm{F}$

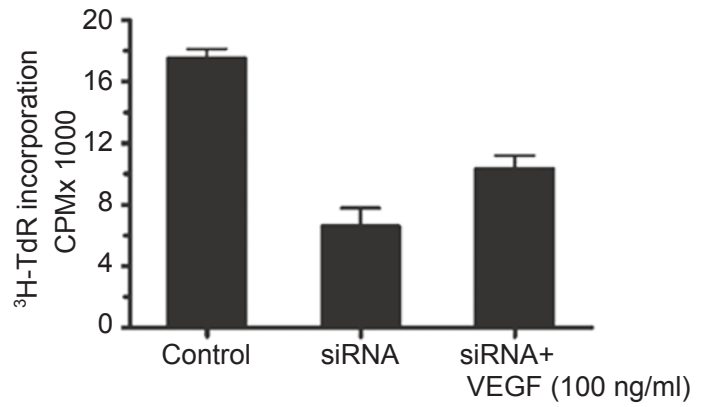

Figure 3 Downregulation of endogenous VEGF expression inhibited the proliferation of NSCs. (A) ZM323881 suppressed NSC proliferation in the absence of exogenous VEGF. (B) RT-PCR showed that VEGF164 was the main isoform expressed in NSCs. VEGF protein production in the NSC culture supernatant also increased progressively with time. (C) VEGF protein production in the culture supernatant by NSCs was reduced after RNA interference of VEGF. (D) VEGF protein production in the lysate of NSCs was reduced after RNA interference of VEGF. (E) Inhibition of endogenous VEGF production by VEGF RNA interference resulted in suppressed proliferation of neural stem cells. (F) Inhibition of NSC proliferation by VEGF RNA interference was partially reversed by addition of exogenous VEGF.

phosphorylation (Figure 4C). Therefore, bFGF-mediated upregulation of Flk-1 via phosphorylation of ERK1/2 was essential for the stimulatory effect of VEGF on NSC proliferation.

\section{Discussion}

Many growth factors may be involved in the regulation of NSC proliferation; however, it is not clear how these growth factors coordinate with each other to carry out this task. In various animal models, VEGF stimulates the proliferation of NSCs and neurogenesis in the CNS, such as the hippocampus $[15,16]$. In adult hippocampus and the subventricular zone, NSCs are found in close proximity to blood vessels and surrounded by glial cells. Other studies suggested that endothelial cells and astroglia cells, which express VEGF and bFGF, stimulate self-renewal and expand neurogenesis of NSCs and may serve as a niche for NSCs $[19,20]$. In the present study, we found that VEGF autocrine plays a role in the regulation of NSC proliferation 
A

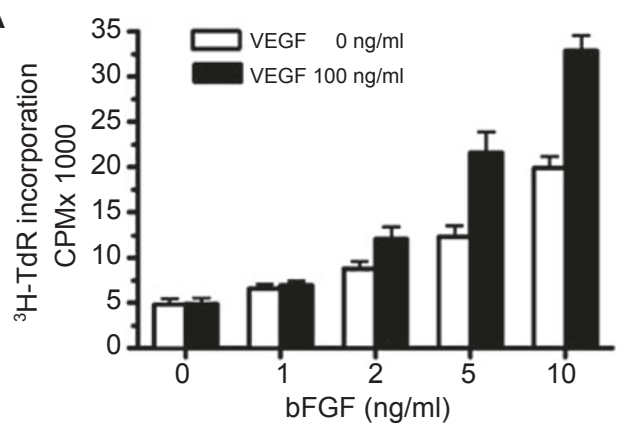

C

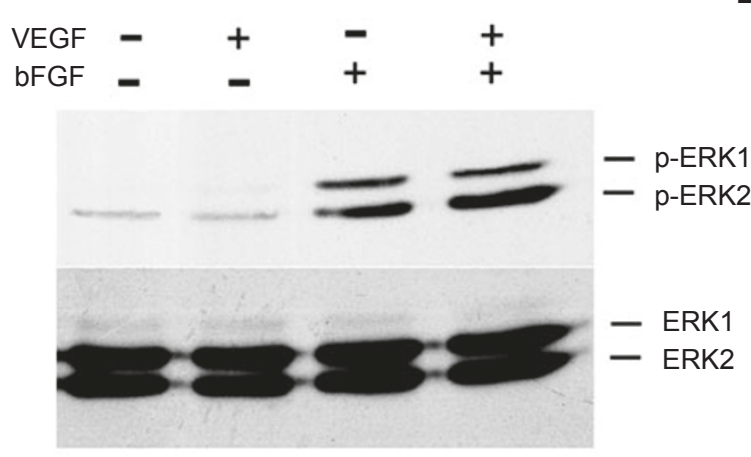

B
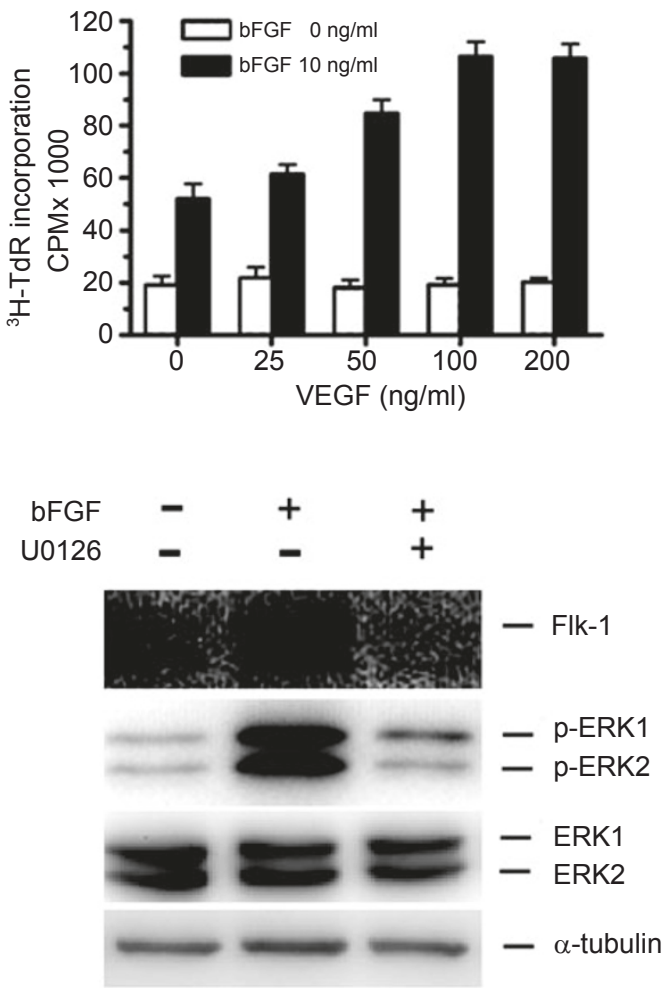

Figure 4 VEGF-induced NSC proliferation was dependent on increased Flk-1 expression level by bFGF via promoting ERK1/2 activation. (A) VEGF and bFGF had additive effects on NSC proliferation. (B) VEGF-induced NSC proliferation was suppressed in the absence of bFGF. (C) Western blotting showed increased amounts of phosphorylated ERK1/2 after addition of bFGF regardless of the presence of VEGF. VEGF alone had no effect on ERK1/2 activation. (D) Increased expression of Flk-1 induced by bFGF was detected by Western blotting, and was abolished when cells were also treated with a specific inhibitor for ERK1/2 phosphorylation.

via Flk-1 (Figure 3). To our surprise, though, unlike the effect of bFGF on NSCs, the effect of VEGF in promotion of NSC proliferation depends on the addition of bFGF. This may be due to the fact that upregulation of Flk-1 by bFGF via phosphorylation of ERK1/2 is essential for the effect of VEGF on NSC proliferation (Figure 4).

It has been reported that VEGF has a biphasic effect on the neural progenitor cells [30]. At low dosages, for instance, $50 \mathrm{ng} / \mathrm{ml}$, VEGF promotes proliferation of neural progenitor cells; at the dosage of $500 \mathrm{ng} / \mathrm{ml}$, however, it enhances neuronal differentiation of adult neural progenitor cells. In our studies, we observed that the massive proliferative effect of VEGF on NSCs peaked at a dosage of 100 $\mathrm{ng} / \mathrm{ml}$. We did not see any effect of VEGF on neuronal differentiation of NSCs at higher dosages. This difference may be due to the fact that the NSCs we used were derived from ES cells and, therefore, were probably less differentiated than progenitor cells used in other studies.

Expansion of NSCs from embryonic day 5.5 (E5.5) to E7.5 epiblast depends on leukemia inhibitory factor (LIF) but not on bFGF. On the other hand, expansion of NSCs from E8.5 neural plate depends on bFGF [31]. Since the NSCs we used are also bFGF-dependent, they may be similar to NSCs from E8.5 neural plate [31] in terms of differential stages. VEGF could also promote NSC proliferation; however, its effect requires the presence of bFGF (Figure 4B). This is because expression of Flk-1 was regulated by the bFGF signal (Figure 4D). This finding confirms the observations by Zhang et al. [32], and we further provide evidence that phosphorylation of ERK upon bFGF stimulation is essential for upregulation of Flk-1 (Figure 4D).

Overall, this study demonstrated that exogenous and/or endogenous VEGF regulates the proliferation of NSCs, and the effect of exogenous VEGF is bFGF dependent. bFGF upregulates the expression of Flk-1 via stimulating phosphorylation of ERK. This novel finding enhances our understanding on how these two growth factors coordinate with each other in regulation of NSC proliferation, and may provide insight into the mechanisms by which microenvironmental niche signals regulate NSCs. 


\section{References}

1 Reynolds BA, Weiss S. Generation of neurons and astrocytes from isolated cells of the adult mammalian central nervous system. Science 1992; 255:1707-1710.

2 Temple S, Davis AA. Isolated rat cortical progenitor cells are maintained in division in vitro by membrane-associated factors. Development 1994; 120:999-1008.

3 Palmer TD, Takahashi J, Gage FH. The adult rat hippocampus contains primordial neural stem cells. Mol Cell Neurosci 1997; 8:389-404.

4 Doetsch F, Scharff C. Challenges for brain repair: insights from adult neurogenesis in birds and mammals. Brain Behav Evol 2001; 58:306-322.

5 Nadarajah B, Parnavelas JG. Modes of neuronal migration in the developing cerebral cortex. Nat Rev Neurosci 2002; 3:423432 .

6 Doetsch F. A niche for adult neural stem cells. Curr Opin Genet Dev 2003; 13:543-550.

7 Carmeliet P, Ferreira V, Breier G, et al. Abnormal blood vessel development and lethality in embryos lacking a single VEGF allele. Nature 1996; 380:435-439.

8 Ferrara N, Carver-Moore K, Chen H, et al. Heterozygous embryonic lethality induced by targeted inactivation of the VEGF gene. Nature 1996; 380:439-442.

9 Weis SM, Cheresh DA. Pathophysiological consequences of VEGF-induced vascular permeability. Nature 2005; 437:497504.

10 Carmeliet P. Angiogenesis in health and disease. Nat Med 2003; 9:653-660.

11 Neufeld G, Cohen T, Gengrinovitch S, Poltorak Z. Vascular endothelial growth factor (VEGF) and its receptors. FASEB J 1999; 13:9-22.

12 Petrova TV, Makinen T, Alitalo K. Signaling via vascular endothelial growth factor receptors. Exp Cell Res 1999; 253:117130.

13 Ferrara N, Gerber HP, LeCouter J. The biology of VEGF and its receptors. Nat Med 2003; 9:669-676.

14 Larrivee B, Lane DR, Pollet I, Olive PL, Humphries RK, Karsan A. Vascular endothelial growth factor receptor-2 induces survival of hematopoietic progenitor cells. J Biol Chem 2003; 278:2200622013.

15 Jin K, Zhu Y, Sun Y, Mao XO, Xie L, Greenberg DA. Vascular endothelial growth factor (VEGF) stimulates neurogenesis in vitro and in vivo. Proc Natl Acad Sci USA 2002; 99:1194611950.

16 Fabel K, Tam B, Kaufer D, et al. VEGF is necessary for exerciseinduced adult hippocampal neurogenesis. Eur J Neurosci 2003; 18:2803-2812.

17 Cao L, Jiao X, Zuzga DS, et al. VEGF links hippocampal activity with neurogenesis, learning and memory. Nat Genet 2004; 36:827-835.

18 Schanzer A, Wachs FP, Wilhelm D, et al. Direct stimulation of adult neural stem cells in vitro and neurogenesis in vivo by vascular endothelial growth factor. Brain Pathol 2004; 14:237248.

19 Shen Q, Goderie SK, Jin L, et al. Endothelial cells stimulate selfrenewal and expand neurogenesis of neural stem cells. Science 2004; 304:1338-1340.

20 Song H, Stevens CF, Gage FH. Astroglia induce neurogenesis from adult neural stem cells. Nature 2002; 417:39-44.

21 Heine VM, Zareno J, Maslam S, Joels M, Lucassen PJ. Chronic stress in the adult dentate gyrus reduces cell proliferation near the vasculature and VEGF and Flk-1 protein expression. Eur J Neurosci 2005; 21:1304-1314.

22 Ford-Perriss M, Abud H, Murphy M. Fibroblast growth factors in the developing central nervous system. Clin Exp Pharmacol Physiol 2001; 28:493-503.

23 Mignatti P, Morimoto T, Rifkin DB. Basic fibroblast growth factor released by single, isolated cells stimulates their migration in an autocrine manner. Proc Natl Acad Sci USA 1991; 88:1100711011.

24 Ciccolini F, Svendsen CN. Fibroblast growth factor 2 (FGF-2) promotes acquisition of epidermal growth factor (EGF) responsiveness in mouse striatal precursor cells: identification of neural precursors responding to both EGF and FGF-2. J Neurosci 1998; 18:7869-7880.

25 Tropepe V, Sibilia M, Ciruna BG, Rossant J, Wagner EF, van DK. Distinct neural stem cells proliferate in response to EGF and FGF in the developing mouse telencephalon. Dev Biol 1999; 208:166-188.

26 Vaccarino FM, Schwartz ML, Raballo R, et al. Changes in cerebral cortex size are governed by fibroblast growth factor during embryogenesis. Nat Neurosci 1999; 2:246-253.

27 Raballo R, Rhee J, Lyn-Cook R, Leckman JF, Schwartz ML, Vaccarino FM. Basic fibroblast growth factor (Fgf2) is necessaryfor cell proliferation and neurogenesis in the developing cerebral cortex. J Neurosci 2000; 20:5012-5023.

28 Li J, Puceat M, Perez-Terzic C, et al. Calreticulin reveals a critical $\mathrm{Ca}(2+)$ checkpoint in cardiac myofibrillogenesis. J Cell Biol 2002; 158:103-113.

29 Okabe S, Forsberg-Nilsson K, Spiro AC, Segal M, McKay RD. Development of neuronal precursor cells and functional postmitotic neurons from embryonic stem cells in vitro. Mech Dev 1996; 59:89-102.

30 Meng H, Zhang Z, Zhang R, et al. Biphasic effects of exogenous VEGF on VEGF expression of adult neural progenitors. Neurosci Lett 2006; 393:97-101.

31 Tamaki W, Jody JH, Masatsugu E, et al. Vascular endothelial growth factor directly inhibits primitive neural stem cell survival but promotes definitive neural stem cell survival. J Neurosci 2006; 26:6803-6812.

32 Zhang H, Laszlo Vutskits, Michael SP, Jozsef ZK. VEGF is a chemoattractant for FGF-2-stimulated neural progenitors. J Cell Biol 2003; 163:1375-1384. 